\title{
Abya Yala em jogo: uma visão decolonial da história de mulheres de Abya Yala no Ensino de Língua Espanhola
}

\author{
Gabrielle Tavares Pereira ${ }^{1}$ \\ Glauco Vaz Feijó²
}

Resumo

O presente artigo se ocupa de relatar a pesquisa de mestrado em educação profissional e tecnológica que culminou na criação de um jogo de tabuleiro bilíngue (Espanhol\Português) que trabalha a história de mulheres de Abya Yala (Américas) que desafiaram a normatização ocidental de racialidade patriarcal e desempenharam papéis divergentes dos estabelecidos pela colonialidade para sua raça e gênero. Para que se chegasse a este objetivo foi percorrido um caminho teórico que perpassou o conceito de identidade e diferença na perspectiva de Stuart Hall; a formação da identidade americana em um contexto de colonialidade; a origem do termo "Abya Yala" e o porquê a substituição de "América"; a perspectiva decolonial e sua contextualização aprofundada na colonialidade do gênero, até chegar à alternativas para superá-la; e a fundamentação teórica com autores que trazem a importância pedagógica do brincar e dos jogos como metodologia de ensino aprendizagem. Há ainda, o relato e a discussão sobre as primeiras aplicações do produto e sobre as correções e alterações que advieram destas, bem como o formato e local onde estará disponível para impressão e utilização de outras e outros docentes que desejem oferecer a seus alunos este momento de interatividade e reflexão. Propõe-se aqui uma alternativa de material educativo para o ensino de língua espanhola, imaginado para a realidade da educação profissional e tecnológica, que colabore com a formação de alunos conscientes das desigualdades sociais, econômicas, políticas, e das relações de poder e capazes de desenvolver práticas de oralidade, de leitura e de escrita interculturalmente situadas.

Palavras-chave: Ensino de espanhol como língua estrangeira. Abya Yala. Decolonialidade.

\section{Resumen}

El presente artículo se ocupa de la investigación llevada a cabo en la maestría en educación profesional y tecnológica, que culminó con la creación de un juego de mesa bilingüe (español/portugués) que trabaja sobre la historia de las mujeres de Abya Yala (América) que desafiaron la normalización occidental de la racialidad patriarcal y desempeñaron papeles divergentes de los establecidos por la colonialidad para su raza y género. Para lograr este objetivo, se recorrió un camino teórico que cruzó el concepto de identidad y diferencia desde la perspectiva de Stuart Hall; la formación de la identidad americana en un contexto colonial; el origen del término "Abya Yala" y por qué se sustituyó "América"; la perspectiva descolonial y su contextualización profunda en la colonialidad del género, hasta llegar a las alternativas para superarla; y la fundamentación teórica con autores que aportan la importancia pedagógica del juego y los juegos como metodología de enseñanza para el aprendizaje. Proponemos aquí un material educativo alternativo para la enseñanza de la lengua española, imaginado para la realidad de la educación profesional y tecnológica, que colabora con la formación de estudiantes conscientes de las relaciones sociales, económicas, políticas y de poder y capaces de desarrollar prácticas de oralidad, lectura y escritura localizadas interculturalmente.

Palabras clave: Enseñanza del español como lengua extranjera. Abya Yala. Descolonialidad.

\footnotetext{
${ }^{1}$ Mestranda em Educação Profissional e Tecnológica, ProfEPT-IFB-CBRA. Instituto Federal de Educação, Ciência e Tecnologia de Brasília (IFB).E-mail: gabrielle.pereira@ifb.edu.br.r

2 Doutor em História. Instituto Federal de Educação, Ciência e Tecnologia de Brasília (IFB). E-mail: glauco.feijo@ifb.edu.br.
} 
1 Introdução

Na história dos conceitos linguísticos, o de língua está entre os mais passíveis a mudanças. Nas transformações do pensamento, sobretudo na grande área das análises da linguagem, visões diferenciadas do que seja a língua têm propiciado posturas distintas na maneira como geramos conhecimento ao realizar pesquisas, no planejamento de cursos, de materiais instrucionais e de metodologias de ensino em língua estrangeira moderna (LEM), no caso específico, em língua espanhola.

O presente artigo não pretende saber qual é a visão mais corrente ou mais aceita no âmbito da academia, e sim eleger visões de língua e de linguagem que colaborem com a formação de alunos capazes de desenvolver práticas de oralidade, de leitura e de escrita situadas socioculturalmente. Para tanto, propõe-se aqui conceber processos didáticos voltados para a construção de vivências na e com a língua alvo, de modo a fortalecer a aprendizagem entre culturas, por meio da qual desigualdades sociais, econômicas, políticas, e relações de poder não sejam mantidas ocultas, mas reconhecidas e confrontadas em condição de respeito, legitimidade mútua, simetria e igualdade.

\subsection{Justificativa}

No universo de possibilidades de ensino encontradas no âmbito dos campido Instituto Federal em que trabalhamos, a LEM permeia quase todas. É curso ou disciplina de formação inicial e continuada, bem como objeto do Ensino Médio Integrado e da Licenciatura em Nível Superior. Em comum, há nessas ofertas a dificuldade de aclarar a importância de compreender que a LEM é parte indissociável de uma sociedade - no caso da língua espanhola, de 21 sociedades - e da construção íntima do tripé língua-história-identidade.

Alunas e alunos, por diversas vezes, privilegiam os momentos da aula em que se estuda a gramática, o léxico, a fonética ou a fonologia, e marginalizam internamente os conhecimentos relacionados à história e à cultura dos/das falantes da língua, ignorando que essa abarca sempre um conjunto de fatores, não sendo um código que se gera e se gere de forma asséptica ou que brote nas academias e literaturas. A/O estudante não o faz por acaso, 
este prestígio dado à gramática advém, muitas vezes, da própria academia, das/dos docentes, e da sociedade, que também carregam estas dissociações.

Além disso, ainda que consigamos vencer estes obstáculos em prol da equivalência entre "o que é mais importante ensinar ou aprender?" e consigamos trabalhar em sala a história e os aspectos culturais dos falantes da língua almejada, nos restará a inquietação de qual história e sobre qual cultura lecionar. Nesse ponto, é importante refletir se pretendemos perpetuar a narrativa eurocêntrica sobre a América e as visões que advieram desta ou se buscaremos outros olhares, menos prestigiados, mas talvez mais legítimos e mais justos.

Relevante pensar também sobre qual cultura trabalharemos. Será a visão de um/a Latino/a Americano/a sedento/a por civilização, que come coisas excêntricas e se veste de forma extravagante para celebrar datas específicas, ou será de um povo que é coletivo, plural, mas também singular, significando datas, fatos e personas de forma crítica $e$ contextualizada?

E, por último, como o faremos? Que metodologias ou métodos seriam capazes de atravessar estas barreiras aproximando os/as estudantes de tais temas de modo a despertar pertencimento, interesse e respeito? Nesse ponto, seguindo as pistas de autores como Velasco (1996), para quem desde o início da civilização, o brincar é uma atividade que independe da idade do/a indivíduo/a uma vez que não se restringe somente à infância, apostamos no jogo de tabuleiro como uma estratégia de ensino-aprendizagem que provoca interesse do/a jogador/a pela temática em foco, permitindo aquisição de conhecimentos e competências, revisão de conteúdo, aumento de atenção, potenciação de interação entre os/as participantes e envolvimento mais intenso em todos os processos. Assim, percorrendo o caminho das reflexões ontológicas e epistemológicas, buscamos chegar à construção de um produto em forma de jogo de tabuleiro que se adequa ao ensino de língua espanhola fundado em uma ética de formação de sujeitos críticos e conscientes de seu lugar no mundo.

\subsection{Pergunta de pesquisa}

Diante dessas considerações, o que se coloca aqui é, se concordamos com Antunes (2009), que a percepção de língua limitada apenas à morfossintaxe, não considerando a 
historicidade e nem a finalidade comunicativa, acaba por restringi-la, impedindo uma visão ampla, separando-a do povo, da identidade e da cultura, e, complementarmente, se acreditamos que a perspectiva sobre o objeto de ensino define as ações que desenvolvemos em sala de aula e que esta concepção permitirá a construção de conjunturas de interação em que se fomente a aproximação/inserção em língua estrangeira, permeadas necessariamente pelos falantes maternos desta língua, por sua história e por sua identidade, cabe então conjeturar: um jogo de tabuleiro como objeto de ensino que trabalhe a história e a cultura de mulheres do território americano, a partir de uma perspectiva decolonial e intercultural, pode coadjuvar para pôr em prática estas concepções?

Neste contexto, a pesquisa teve como objetivo geral a formulação de um jogo de tabuleiro em língua espanhola para trabalhar a história de mulheres de Abya Yala desde uma perspectiva decolonial e intercultural e a análise da aplicação deste produto em sala de aula.

Esse objetivo geral foi perpassado por outros objetivos mais precisos: 1) conhecer uma narrativa decolonial de Abya Yala; 2) dar destaque a algumas mulheres que participaram da história deste território; 3) construir um jogo de tabuleiro que trabalhe esta temática; 4) aplicá-lo em diferentes turmas do Ensino Médio; 5) analisar e avaliar a articulação e os efeitos da utilização desta metodologia.

\section{Referencial teórico}

Para construir o arcabouço necessário para construir um jogo que vá ao encontro das concepções pretendidas e para que a aplicação deste produto contribua de maneira efetiva para a formação omnilateral das/dos estudantes, apoiamo-nos em uma base teórica fundada em seis pilares, a saber: 1) conceito de identidade; 2) a formação da identidade americana em um contexto de colonialidade; 3) por que Abya Yala?; 4) a opção decolonial; 5) a intersecção raça-gênero; e 6) jogos de tabuleiro como metodologia de ensino-aprendizagem.

\subsection{Identidade}

A natureza do termo é em si extremamente complexa, visto que pode expressar tanto atributo do análogo e do comum, como reunião de caráter peculiar e exclusivo. Por este 
motivo, inferimos que esta construção simbólica, suposta pela adesão de sentimentos, constitui-se, reiteradamente, em relação a um "outro". Para Silva (2011), afirmar que "ele/a é peruano/a" resguarda uma série de negações em que "ele/a não é argentino/a", "ele/a não é brasileiro/a", enfim que ele/a é aquilo que eu não sou, ou seja, eu sou aquilo que ele/a não é. Ainda segundo Silva (2011), a identidade e a diferença, se traduzem, deste modo, nessas declarações sobre quem pertence e quem não pertence, delimitando fronteiras, classificando e formalizando. Portanto, elas não podem ser desassociadas de amplas relações de poder.

Hall (2011) igualmente nos afirma que a identidade é constituída através da diferença e não fora dela, e toda identidade só é estabelecida em relação a um Outro, o exterior constitutivo, àquilo que lhe falta. Desta forma, a identificação pode advir de fora para dentro, ou seja, a partir do outro; ou de dentro para fora, ou seja, em relação ao outro.

Ao optar por trabalhar a língua inserida socioculturalmente, ao trazer o "hispanohablante" para a sala de aula, será necessário oferecer sobre esse, dados, informações, sob as quais as alunas e os alunos formarão seus conceitos e construirão, para eles/elas e com eles/elas, identidades baseadas nas referências que tiveram contato ao longo da vida, nas que tem contato naquele momento, num contínuo movimento de formação de um “outro", mas também de identificação e de diferença.

Neste sentido a relevância de novos olhares que, alicerçados na decolonialidade e na interculturalidade, possibilitem àlao estudante rever ou conhecer a história do outro inquietando-se e questionando a sua própria história.

2.2 A identidade americana em um contexto de colonialidade

O roubo mais importante do processo colonial é a memória de quem somos: o espelho. (SEGATO, 2018)

No primeiro artigo do seu livro "Inferno Atlântico", denominado "América Diabólica", Souza (1993) conta que o europeu que chegou à América, que a colonizou e que escreveu as primeiras estórias sobre o novo Mundo, figurava o mundo de forma maniqueísta: 
Se Europa e suas instituições eram (...) a representação do bem, a América passava imediatamente para a posição do mal: o demônio e as bruxas e feiticeiras. Assim, ao produzir uma imagem pejorativa da América, o europeu enaltecia sua posição de local onde triunfava o bem e a lei de Deus, numa dupla construção identitária que fundamenta a construção da colonialidade do ser. (SOUZA, 1993, p. 37).

Sendo assim, é necessário advertir que os textos de construção identitária produzidos na América Latina no século XIX possuem como legado essa construção identitária colonial cheia de juízos de valor e de fetichismos e com ela dialogam, mesmo que seja para negá-la, como é o caso da imaginação de uma América Latina bolivariana. Segundo Bolívar, a América Latina precisa da união, “já que tem uma origem, uma língua, mesmos costumes e uma religião, devendo, por conseguinte, ter um só governo que confederasse os diferentes Estados que haverão de se formar". (BOLÍVAR, 1815, p. 28)

Se, para Bolívar, a origem colonial tem, por si mesma, o papel legitimador da ideia de União, sem a qual a América seria um projeto fadado ao fracasso, Sarmiento lerá esse mesmo passado de forma diferente quando viaja em direção a Europa e aos Estados Unidos, buscando modelos a serem seguidos por seu país (PRATT, 1999). Antes mesmo de atingir os seus destinos, o percurso já fornece a Sarmiento pistas sobre suas leituras acerca da Argentina que almejava civilizar. Para ele, os indígenas e gaúchos que habitavam os pampas eram indolentes para "possuir" as grandes extensões de terras vazias, e as razões se deviam a uma incapacidade advinda, entre outros, de sua impureza racial. A proposta de importação de europeus para cultivar as terras se mostrou, no entanto, de difícil execução, o que o levou a oferecer, seu próprio livro para realizar o trabalho de civilização dos povos originários: “Envíole, pues, el Facundo sin otras atenuaciones, y hágalo que continúe la obra de rehabilitación de lo justo y de lo digno que tuvo en mira al principio" (SARMIENTO, 1845, p. 35). Desvela-se aqui a mentalidade maniqueísta presente nas fundações das identidades latino-americanas influenciando o seu discurso, que é marcado pela dualidade entre a civilização e a barbárie, conceito tão presente no imaginário latino americano.

Também a apreciação do feminino nas narrativas coloniais vem sempre acompanhada do olhar eurocêntrico. É necessário estar atento à ótica dos historiadores e escritores que incutem sentidos para as práticas e conhecimentos dos povos originários, retratando um mundo indígena a partir de princípios androcêntricos e cristãos. Segundo Navarro-Swain, pesquisadora da historiografia sobre mulheres indígenas no Brasil colonial, na tentativa de 
incluir outras culturas na história, colonizaram sob a baliza do mesmo, os contrastes que, de outra forma, poderiam pôr a prova os conceitos generalizantes a respeito do feminino e do masculino. Segundo ela,

os indícios referentes às sociedades indígenas são silenciados ou transformados, segundo as condições de imaginação e de possibilidade de quem os decodifica e 0 gênero disto não está ausente. [...] Os eixos de coesão social nem sempre estão fixados no sexo, na sexualidade ou na dominação de uns pelos outros, mas esta diversidade é apagada na política discursiva do silenciamento, modo de significação constitutivo de uma realidade que se apresenta como verdadeira e os costumes indígenas são soletrados no masculino. [...] 0 que, senão o discurso da ordem "natural" heterossexual e reprodutora, veria submissão onde havia liberdade, obrigações onde havia escolhas, obediência onde havia trocas? (NAVARRO-SWAIN, 2008, p. 02).

À luz desta concepção e cientes da vigília constante, acreditamos ser viável romper com as origens coloniais, basilares da própria ideia de identidade latinoamericana, e contribuir para a formação de um "Pensamento-Outro" apoiado no princípio da responsabilidade de posicionar-se contra a não-existência, a existência dominada e a desumanização e compartir com os alunos de LEM uma visão de América que se distinga da narrativa colonial, na qual latino/a-americano/a é ou sujeito impotente subjugado por penalidades históricas, ou o/a selvagem sedento/a pela redenção civilizatória. Para tanto, oferecemos como contraponto 0 reconhecimento dos fatos, das identidades individuais e coletivas de sujeitos históricos, reforçando o caráter da união continental, encarando as desigualdades sociais, econômicas e políticas por meio de um intercambio, que possibilite a construção de saberes e práticas culturalmente diversas, buscando desenvolver um novo sentido entre elas.

\subsection{Por que Abya Yala}

Abya Yala é uma nomenclatura de autodesignação dos povos originários do continente como contraponto à América com o objetivo de construir um sentimento de resistência, unidade e pertencimento. Segundo Porto-Gonçalves,

Na sua língua de origem, a lingua Kuna, Abya Yala significa "Terra madura", "Terra Viva" ou "Terra em florescimento". O povo Kuna é originário da Serra Nevada no norte da Colômbia, tendo habitado a região do Golfo de Urabá e das montanhas de 
Darien e vive atualmente na costa caribenha do Panamá na Comarca de Kuna Yala (San Blas) (PORTO-GONÇALVES, s.d, s.p.).

A expressão foi utilizada manifestamente com cunho político pela primeira vez em 2004 na // Cumbre Continental de los Pueblos y Nacionalidades Indigenas de Abya Yala, realizada em Quito. Em 2007, se estabeleceu a Coordenação Continental das Nacionalidades e Povos Indígenas de Abya Yala com o objetivo de construir um espaço para "convergir experiências e propostas, para enfrentar as políticas de globalização neoliberal e lutar pela liberação definitiva de nossos povos irmãos, da mãe terra, do território, da água e de todo patrimônio natural para viver bem" (DECLARACIÓN DE INXIMCHE', 2007).

Desta forma, Abya Yala, mais que uma nova nomenclatura, carrega em si uma nova perspectiva que dá voz a sujeitos silenciados e subalternizados em termos políticos e devolve o poder, dentre outras coisas, de nomear-se, encontrando sentido para si e para os seus.

\subsection{A opção Decolonial}

O termo decolonial deriva de uma perspectiva teórica que se fundamenta na possibilidade de um pensamento crítico que se contraponha à perspectiva dominante eurocêntrica de construção do conhecimento histórico e social.

Esta perspectiva foi e vem sendo cunhada por um conjunto de autores denominado por Escobar (2003) como grupo de pesquisadores do projeto "Modernidade/Colonialidade" (MC). Aos autores do projeto, foram se juntando várias outras autoras e autores ao longo da última década, alguns trazendo mesmo críticas pertinentes às primeiras elaborações do grupo, buscando avançar na crítica decolonial, sobretudo no que diz respeito à colonialidade de gênero não muito bem trabalhada em um primeiro momento.

O primeiro conceito basilar da perspectiva teórica Modernidade/Colonialidade se refere ao mito de fundação da modernidade. A modernidade foi forjada a partir de uma violência colonial. Em outras palavras, após a conquista da América, os europeus conceberam o mito de que o conhecimento produzido pela Europa era universal, negando a racionalidade do outro não europeu. Segundo Dussel (2005), a Europa firmou uma razão universal a partir 
de si e estabeleceu uma conquista epistêmica na qual o etnocentrismo europeu colocou-se como o único habilitado a pretender uma identificação com a "universalidade-mundialidade".

O segundo conceito está diretamente vinculado com o primeiro. Segundo MaldonadoTorres (2007), o termo colonialidade vem da perspectiva de que apesar do fim do colonialismo, o padrão de poder que aflorou como resultado dele não se limitou a uma relação formal de poder entre os povos ou nações durante a sua ocorrência, mas se alastrou até determinar a forma como o trabalho, o conhecimento, a autoridade e as relações intersubjetivas se articulam entre si através do mercado capitalista mundial e da ideia de raça. Sendo assim, a colonialidade sobrevive até hoje "nos manuais de aprendizagem, nos critérios para os trabalhos acadêmicos, na cultura, no senso comum, na autoimagem dos povos, nas aspirações dos sujeitos, e em tantos outros aspectos de nossa experiência moderna". (Maldonado-Torres, 2007, p. 127)

A modernidade está, então, sujeita à existência da colonialidade e se estabelece sobre três bases principais, a colonialidade do poder, a colonialidade do saber e a colonialidade do ser, às quais Lugones acrescenta a colonialidade de gênero.

O terceiro conceito basilar é o de racismo epistêmico. Se a colonialidade forjou a inferioridade de grupos humanos não europeus sob a ótica da produção da divisão racial do trabalho, da produção cultural e dos conhecimentos, foi necessário atuar também na negação cognitiva nos sujeitos subjugados.

Neste sentido, o racismo epistêmico não reconhece nenhuma outra teoria de conhecimento, de produção, de pensamento crítico ou científico. Isto é, a recusa em reconhecer que a produção de conhecimento de pessoas ou grupos seja válida por duas razões: porque não são brancas ou porque as pesquisas e resultados da produção de conhecimento envolvem repertório e cânones que não são ocidentais.

A perspectiva teórica decolonial formula conceitos alternativos à colonialidade, como “diferença colonial”, “transmodernmidade”, interculturalidade crítica e pedagogia decolonial.

Introduzido por Mignolo (2003), a diferença colonial significa pensar a partir das ruínas e das margens criadas pela colonialidade na estruturação do mundo moderno/colonial, como forma de intervir em um novo horizonte epistemológico. 0 que se produz fora da modernidade eurocêntrica, por sujeitos subalternizados, pode ser identificado como diferença colonial. 
O conceito de transmodernidade, formulado por Dussel (2005), refere-se à proposta de realização de um processo de integração, que inclui a "modernidade/alteridade" mundial (Dussel, 2005, p. 66) e aponta para todos os aspectos que se situam além das estruturas valorizadas pela cultura euroamericana moderna e que atualmente estão em vigor nas grandes culturas universais e foram se movendo em direção a uma utopia pluriversal, como ilustrado na imagem abaixo:

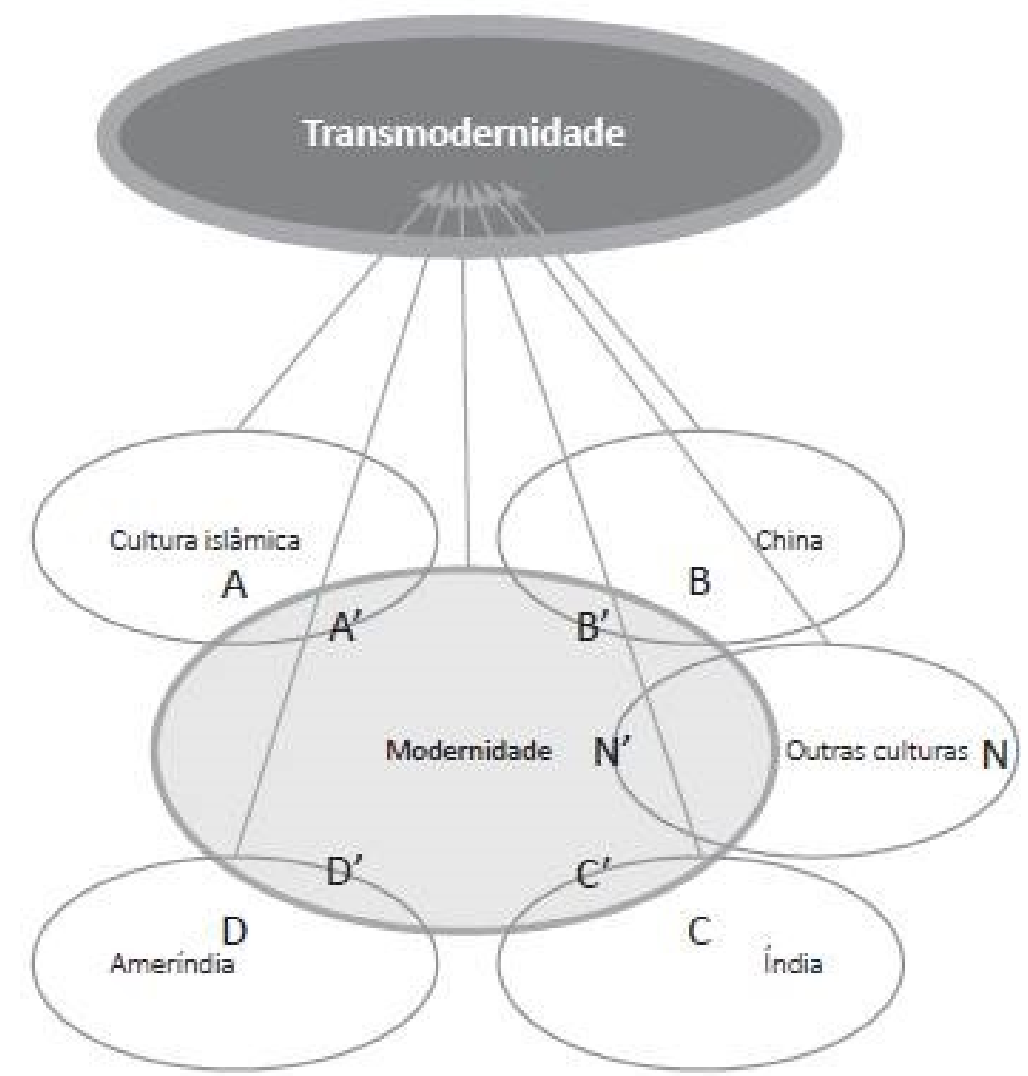

Imagem 1. A transmodernidade de Enrique Dussel. Fonte: Dussel, 2016, p. 63.

Grosfoguel (2016) afirma que apesar de que tudo tenha sido afetado pela Modernidade eurocêntrica, ainda existem perspectivas epistêmicas não ocidentais, que guardam uma exterioridade relativa da Modernidade eurocêntrica. Elas foram afetadas pelo genocídio/epistemicídio, mas não foram completamente destruídas. É esta exterioridade relativa que, de acordo com Enrique Dussel, propicia esperança e possibilidade de um mundo transmoderno: "um mundo onde muitos mundos são possíveis" 
Por fim, temos a interculturalidade crítica e a pedagogia decolonial. A interculturalidade crítica é processo e projeto político, caracterizando-se como ferramenta dos sujeitos subalternizados e dos movimentos sociais. Para Walsh,

a interculturalidade crítica significa a (re)construção de um pensamento críticooutro - um pensamento crítico de/desde outro modo -, precisamente por três razões principais: primeiro porque está vivido e pensado desde a experiência vivida da colonialidade (...); segundo, porque reflete um pensamento não baseado nos legados eurocêntricos ou da modernidade e, em terceiro, porque tem sua origem no sul, dando assim uma volta à geopolítica dominante do conhecimento que tem tido seu centro no norte global $(2005$, p. 8).

Essa interculturalidade representa a construção de um novo espaço que promova a interação entre os conhecimentos subalternizados e os ocidentais, rebatendo a hegemonia deste e a invisibilização dos outros. Este conceito se relaciona com as questões educacionais através da denominada pedagogia decolonial, que consiste em expressar o colonialismo que construiu a desumanização dirigida pela modernidade europeia e pensar na possibilidade de crítica teórica epistêmica.

Esta perspectiva é pensada a partir da ideia de uma prática que se contraponha à geopolítica, no nosso caso, a uma práxis docente, monocultural e monorracial, pois trata-se de dar visibilidade e enfrentar as estruturas e instituições que têm como horizonte de suas práticas e relações a racialização do mundo e a manutenção da colonialidade. Enfim, para iniciar um diálogo intercultural "autêntico" tem que haver uma explicitação das causas do não diálogo, e isto passa, necessariamente, pela crítica à colonialidade.

Decolonizar, seria então, no campo educacional, efetivar uma práxis educativa propositiva - e não somente denunciativa - por isso o termo "DE" e não "DES" onde o termo insurgir representa a criação e a construção de novas condições sociais, políticas e culturais e de pensamento. (CRUZ; OLIVEIRA, 2016, p.125)

Em outros termos, a construção de uma visão pedagógica que se projeta muito além dos processos de ensino e de transmissão de saber, uma pedagogia concebida como política cultural. Decolonizar na educação é construir pedagogias outras além da hegemônica. Uma perspectiva de educação decolonial requer pensar a partir dos sujeitos submetidos à colonialidade e excluídos das lógicas educativas hegemônicas. 


\subsection{A intersecção raça-gênero}

Ainda que a perspectiva decolonial - especialmente seu olhar sobre a criação da raça como produto da colonialidade europeia - seja fundamental para compreender o sistema então criado e que nos organizou dali até hoje, imaginar que a raça é a única categoria que forma o sistema-mundo da colonialidade é insuficiente, e até certo ponto essencialista, uma vez que invisibiliza outras categorias centrais, como gênero (Mendoza, 2010, p. 24), ao tomar o sexo como um dado da natureza, organizado e organizando sempre da mesma forma as relações entre os sujeitos. Diante dessa crítica, passa a ser realizada uma interpretação feminista da colonialidade - ou um feminismo decolonial - para pensar como as normas de gênero fazem parte da colonialidade do poder, do saber e do ser e como estas relações, embora construídas em um passado aparentemente distante, se fazem presentes e causam efeitos cotidianos levando ao que a autora Grada Kilomba (2019) traz como a experiência de trauma "O colonialismo é uma ferida que nunca foi tratada. Dói sempre, por vezes infeta, e outras vezes sangra". Kilomba afirma que:

de repente, o colonialismo é vivenciado como real - somos capazes de senti-lo! Esse imediatismo, no qual o passado se torna presente e o presente passado, é outra característica do trauma clássico. Experiencia-se o presente como se estivesse no passado. Por um lado, cenas coloniais (passado) são reencenadas através do racismo cotidiano (presente) e, por outro lado, o racismo cotidiano (o presente) remonta cenas do colonialismo (o passado). (KILOMBA, 2019, p. 158)

A criação de uma matriz normativa de gênero, entendida como uma forma de negativa de humanização a determinados corpos é um produto da colonialidade e tem, em si, um componente racial: a criação da norma do gênero como domesticidade e reprodução como ideal de "cultura", “civilidade”, “racionalidade”, que coloca a branquitude como ideal, oposto a práticas, comportamentos, vivências, corpos, e experiências "selvagens", “naturais", “irracionais". As imagens, estereótipos e marcas do gênero estão formadas nessa mesma cadeia histórica que tem a lógica europeia como lógica universal, ou seja, são elaborados no performativo da colonialidade (SEGATO, 2012). 
O gênero se torna categoria de análise decolonial como forma de investigar o que a colonialidade do gênero apagou, destruiu ou invisibilizou no percurso da história e como as noções de gênero da modernidade colonial, que hoje discutimos ou combatemos, são construções que usam da raça e do sexo de modo articulado para preencher a oposição entre humanos e não-humanos. Usar o gênero como categoria de análise decolonial significa empreender estudos que vejam que o que hoje entendemos ou usamos como sexo/gênero foi construído sob a perspectiva da colonialidade, tendo raça e sexo/gênero não como conceitos separados, mas forjados numa mesma matriz que tem como estrutura central o binarismo humanos/não-humanos (subhumanos). (Segato, 2012)

Ao optar por trilhar um caminho de uma educação decolonial feminista, o objetivo do produto Abya Yala em jogo é submergir à diferença colonial e exibir as fragilidades da narrativa europeia ao trazer personagens históricas que, mesmo imersas em um contexto colonial, infringiram a normativa designada a sua raça/gênero, de "domesticidade", "fragilidade", "passionalidade" ou "racialidade" e executaram papeis sociais marginais a esta normativa, pondo à prova, não só a imperatividade, mas também a naturalidade da narrativa colonial.

\subsection{Jogos de Tabuleiro como metodologia de ensino-aprendizagem}

Aprender brincando torna-se parte integrante da ação educadora por prover o emprego do elemento lúdico como forma de atrair a atenção do aprendiz, convidando-o a experimentar um universo contextualizado ao objeto epistêmico em consideração (SILVA, 2010). Estudos da neurociência afirmam que além de estimular as conexões cerebrais e dar suporte às habilidades cognitivas, os jogos ensinam habilidades sociais, como compartilhar com os outros, construir um pensamento crítico, disciplina, paciência e análise de consequências, além de exercitar a memória e as habilidades de tomadas de decisão.

Segundo Moreno (2003), essa estratégia tem papel de facilitadora na condução fazendo com que o campo de investigação, análise e compreensão da conduta humana em seus diversos determinantes sejam ampliados, ou seja, o procedimental, o atitudinal, entre outros. 
Em se tratando da aplicabilidade dessa estratégia para jovens e adultos, os jogos vão ao encontro das suas necessidades, porque eles preferem assumir a responsabilidade pela sua aprendizagem e veem integrados os seus próprios conhecimentos, desafiando assim as atuais perspectivas de educação (FERNANDES, 2015).

Por todas estas razões e observando o público para quem foi proposto, jovens e adolescentes do Ensino Médio integrado, pareceu adequado que o produto gerado por esta pesquisa fosse um jogo. A eleição pelo formato de tabuleiro em detrimento de uma plataforma digital, levou em conta alguns outros fatores:

1. A não dependência de aparatos digitais, como computadores, internet ou celulares para que o produto educacional possa ser utilizado.

2. A relação afetiva com atividades desempenhadas na infância. Como o público alvo do produto são os/as alunos/as do ensino médio integrado, e esses/as têm entre 14 e 19 anos, é possível/provável que em sua infância tenham tido contato com jogos de tabuleiro. A pretensão com isso é acessar a memória afetiva.

Outro ponto importante no processo de construção do produto foi a aposta de que é possível aprender e refletir com o próprio jogo, fugindo da hipótese de que a ludicidade apenas pode ser utilizada em âmbito educacional como "pré ou pós-texto", para divertir antes da parte "séria" ou relaxar após a parte "séria".

Embora seja perfeitamente possível inserir o Abya Yala em Jogo em uma sequência didática e inclusive necessário que se faça uma contextualização nos casos de sua aplicação, o objetivo principal do produto, que é inquietar e questionar a narrativa histórica territorial americana, pretende ser alcançada pelo jogo em si.

\subsection{0 produto}

Partindo das premissas explicitadas anteriormente, a presente pesquisa se ocupou de formular como produto um jogo de tabuleiro em língua espanhola, que trabalhe a história de mulheres de Abya Yala desde uma perspectiva decolonial e intercultural, na pretensão de promover o conhecimento de uma nova narrativa ou gerar inquietação em relação a anteriormente conhecida, de forma intrigante, divertida e colaborativa. 
O produto foi inspirado no jogo T.I.M.E Store, um misto de Role-Playing Game (RPG), um gênero de jogo no qual os jogadores assumem o papel de personagens imaginários em um mundo fictício observando as características e histórias de seus personagens, com a experiência de tabuleiro. 0 enredo do jogo consiste basicamente em uma viagem no tempo realizada por uma empresa, que é responsável por proteger a humanidade, impedindo falhas temporais. Os agentes da empresa incorporam receptáculos que viajam no tempo e tentam encontrar as falhas e resolvê-las coletivamente utilizando habilidades específicas e cobrindo as fraquezas do grupo a fim de descobrirem a falha e vencerem juntos. É, portanto, um jogo colaborativo.

No caso do Abya Yala em jogo, as receptáculas são mulheres da América Hispânica que desempenharam um papel importante no local e no tempo em que viveram, na luta pela liberdade, pela dignidade e pelo respeito. Estas personagens juntas têm que usar suas habilidades para voltar a 1492 e impedir a colonização das Américas. Neste caminho encontram desafios e enigmas que devem desvendar. A proposta é trabalhar a história não contada destas mulheres e da própria América através delas.

A escolha das personagens que servem de receptáculas atendeu ao critério de pluralidade local e temporal. Foram eleitas buscando contemplar diferentes momentos históricos contemporâneos e posteriores à colonização (Séculos XVI, XVII, XVIII, XIX, XX e XXI) e diferentes localidades de Abya Yala (Território Inca, Asteca, Cuba, México, República Dominicana, Argentina e Uruguai).

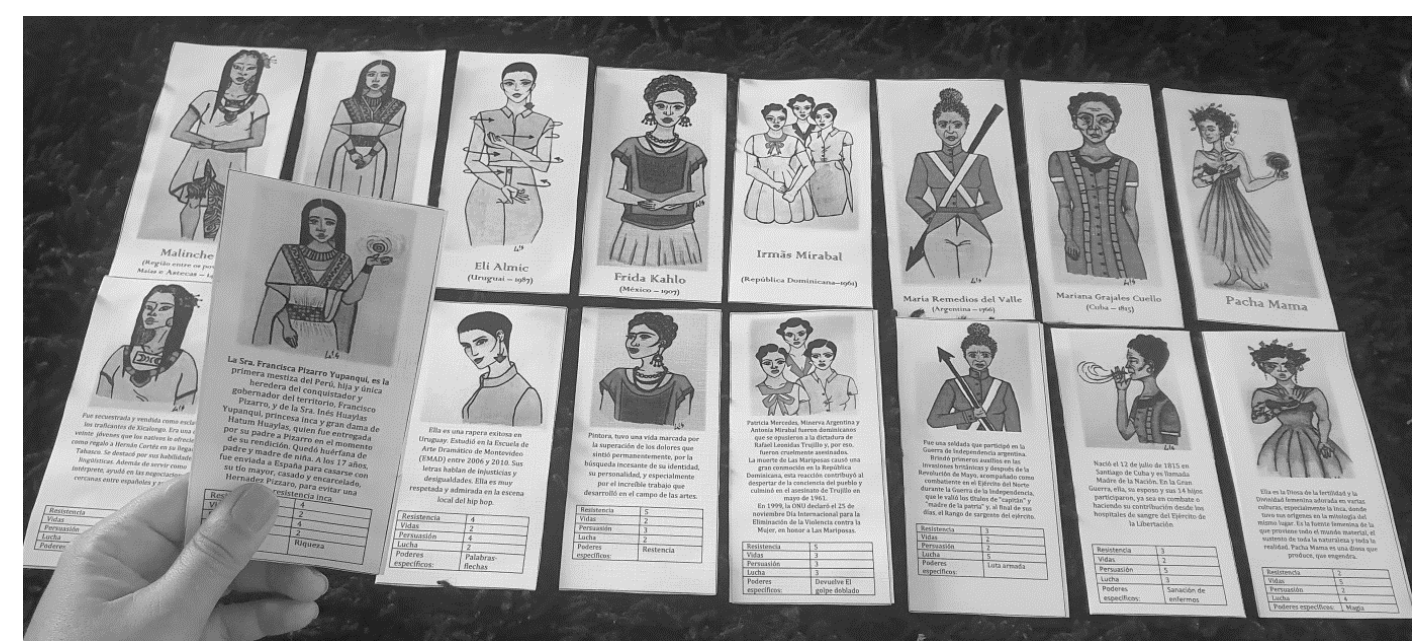

Imagem 2. Cartas Personagens (Frente e verso). Ilustradora: Lisandra Lélis. 
A ilustração ficou por conta de Lisandra Lélis, estudante do $3^{\circ}$ ano do Ensino Médio integrado. A artista realizou longa pesquisa que a muniu de informações sobre cada personagem e relatou a preocupação de que as personagens não fossem estereotipadas ou sexualizadas.

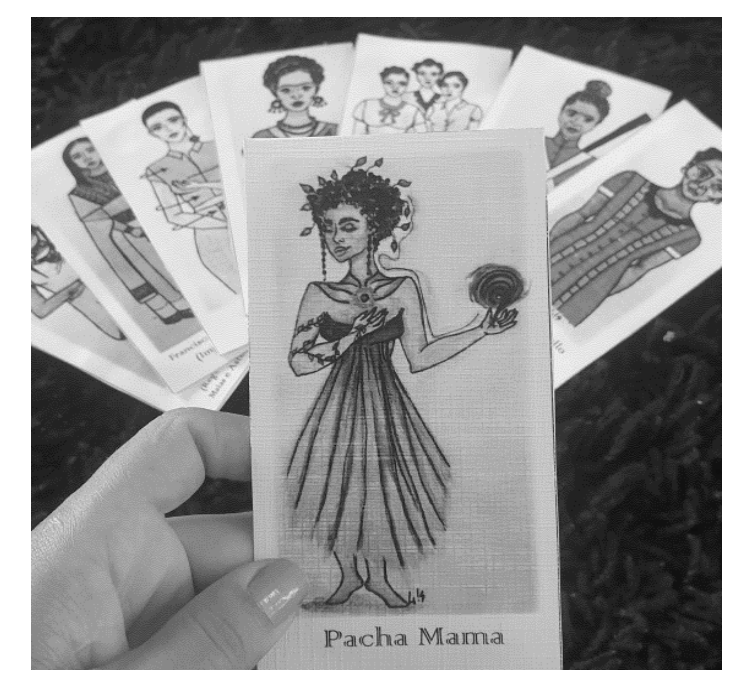

Imagem 3. Cartas Personagens (Frente) Ilustradora: Lisandra Lélis

O desafio inicial do jogo é voltar a momentos específicos da história das personagens e vencer juntas enigmas ou batalhas. A intenção é trazer a história em si da personagem em foco, evidenciando as situações vividas por elas neste contexto colonial, desafiando os/as participantes a se unirem por uma causa teoricamente individual, mas intrinsecamente coletiva.

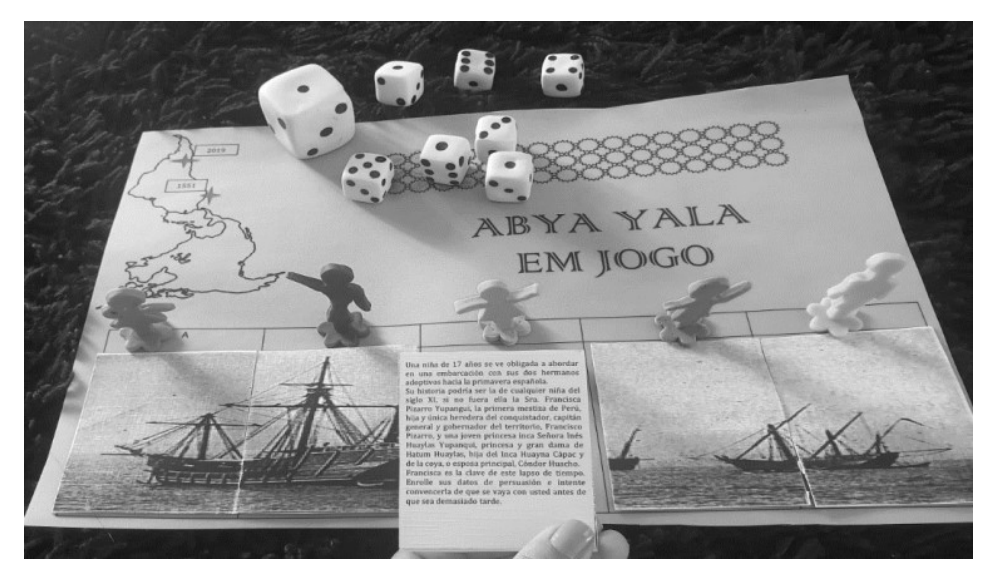

Imagem 4. Carta cenário - Perú 1551.

Ilustradora: Lisandra Lélis. 
O desafio final será voltar a 1492 e evitar a colonização Espanhola. A escolha do obstáculo atende a perspectiva decolonial de que a modernidade, tal como conhecemos, tem sua origem na colonização americana. Conforme Q̨uijano,

A globalização em curso é, em primeiro lugar, a culminação de um processo que começou com a constituição da América e do capitalismo colonial/moderno e eurocentrado como um novo padrão de poder mundial. Um dos eixos fundamentais desse padrão de poder é a classificação social da população mundial de acordo com a ideia de raça, uma construção mental que expressa a experiência básica da dominação colonial e que desde então permeia as dimensões mais importantes do poder mundial, incluindo sua racionalidade específica, o eurocentrismo. Esse eixo tem, portanto, origem e caráter colonial, mas provou ser mais duradouro e estável que o colonialismo em cuja matriz foi estabelecido. Implica, consequentemente, num elemento de colonialidade no padrão de poder hoje hegemônico." (QUIJANO, 2005, p.227-278)

Ainda segundo Q̨uijano, é neste momento também que a América se institui como 0 primeiro espaço/tempo de um padrão de poder de vocação mundial e, desse modo e por isso, como a primeira identidade da modernidade.

Dois processos históricos convergiram e se associaram na produção do referido espaço/tempo e estabeleceram-se como os dois eixos fundamentais do novo padrão de poder. Por um lado, a codificação das diferenças entre conquistadores $e$ conquistados na ideia de raça, ou seja, uma supostamente distinta estrutura biológica que situava a uns em situação natural de inferioridade em relação a outros. Essa ideia foi assumida pelos conquistadores como o principal elemento constitutivo, fundacional, das relações de dominação que a conquista exigia. Nessas bases, consequentemente, foi classificada a população da América, e mais tarde do mundo, nesse novo padrão de poder. Por outro lado, a articulação de todas as formas históricas de controle do trabalho, de seus recursos e de seus produtos, em torno do capital e do mercado mundial. (QUIJANO, 2005, p.128). 


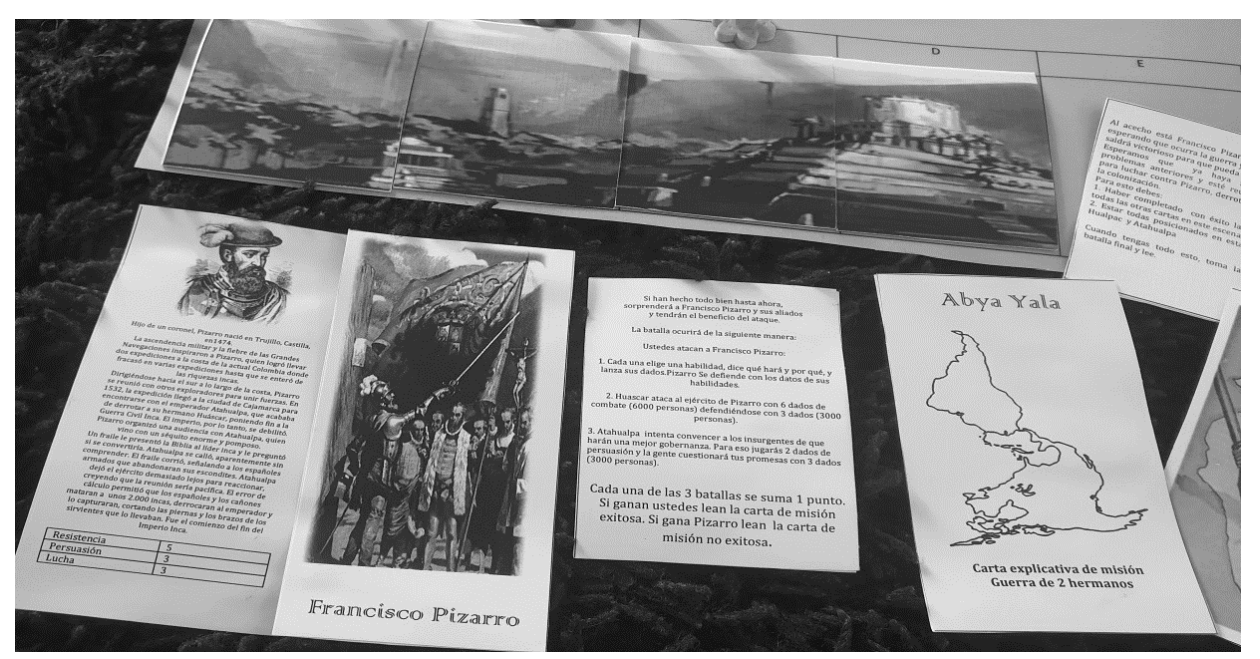

Imagem 5: Cartas desafio final - Expedição Francisco Pizarro. Ilustradora: Lisandra Lélis.

Estes são os parâmetros que nortearam o produto, mesclando a história contada, a negligenciada, a interpretação e as escolhas que farão os/as alunos/as em um processo de conhecimento, reconhecimento e coletividade.

\section{Procedimentos Metodológicos}

O estudo tem caráter experimental, baseado na pesquisa-ação, que preconiza 0 acompanhamento das etapas da pesquisa buscando melhorar a prática através de variações sistematizadas por meio das ações vivenciadas e apurações baseadas nestas vivências.

Seguindo estes parâmetros, aplicamos um protótipo do jogo em um primeiro grupo focal, a fim de perceber possíveis problemas e cabíveis aprimoramentos. Em um segundo momento, fizemos a aplicação em um segundo grupo, com o produto completo e já com as melhorias oriundas da avaliação da primeira aplicação. Posteriormente serão realizadas ainda duas outras aplicações, sempre observadas sugestões de possíveis adequações para que, ao final, seja realizada a impressão definitiva do produto, para devida disponibilização na plataforma EDUCAPES.

Os procedimentos metodológicos foram organizados para serem executados na seguinte ordem: 1) pesquisa e formulação de arcabouço teórico; 2) escolha das personagens e do formato do jogo; 3) construção teórica e física do jogo; 4) aplicação do protótipo; 5) 
aprimoramento do produto; 6) aplicação teste em situação real; 7) aprimoramento do produto; 8) escolha dos grupos de aplicação de pesquisa; 9) aplicação e análise do produto e dos efeitos da utilização desta metodologia no $1^{\circ}$ grupo de pesquisa; 10) aprimoramento do produto; 11) aplicação e análise dos efeitos da utilização desta metodologia no $2^{\circ}$ grupo; 12) análise final das aplicações e de todo o processo.

Para a coleta de dados, aplicaremos nos grupos de pesquisa, antes do início do jogo, um questionário com alternativas objetivas de resposta composto por perguntas à luz da perspectiva decolonial sobre a América Latina e sobre as personagens que serão trabalhadas no produto. Após a aplicação do jogo, os alunos responderão a um novo questionário com 0 mesmo conteúdo para verificação de aprendizagem de conteúdos factuais e conceituais e com outras perguntas que servirão para a avaliação do produto. Os conteúdos atitudinais e procedimentais, além de outros conceituais e factuais, serão observados e relatados ao longo da aplicação do produto. Os dois primeiros grupos que acessaram o jogo em aplicações teste não responderam aos questionários já que estavam sendo avaliadas questões mais técnicas, como a jogabilidade e se os processos previstos, expostos a distintas hipóteses de ação e interação entre os jogadores, resultariam em continuidade ao final do jogo, como o esperado.

Os questionários pré e pós-teste foram elaborados observando o trabalho de Priscila de Souza Chisté Leite (Leite, 2018) sobre a validação de materiais educativos. Essa autora presidiu uma comissão de avaliação de produtos educativos, e em pesquisa, sugeriu uma avaliação baseada em Kaplún (2003), que parta de práticas pedagógicas concretas, ou seja, que a análise do material seja realizada em condições reais e não em uma prova de laboratório em condições especiais. Percorrendo seu caminho de pesquisa, Leite encontrou outro trabalho inspirado nas propostas de Kaplún: a pesquisa de Ruiz et al (2014), que resultou na elaboração de uma cartilha intitulada "Producción de materiales de comunicación y educación popular". O objetivo da cartilha era oferecer ferramentas para a construção de materiais de forma participativa, respeitando os direitos humanos e a diversidade de gênero, e conhecer e experimentar diferentes formatos, estilos e linguagens no processo de produção do material, abordando suas possibilidades de validação participativa.

A cartilha contém perguntas-chave que estimulam a reflexão crítica sobre o processo de produção de materiais educativos e sugerem a organização de um guia de perguntas a 
partir de cinco componentes: “atração, compreensão, envolvimento, aceitação e mudança da ação." Esse guia serviu de sul para a elaboração das questões voltadas para a validaçãolavaliação do produto educacional presentes no questionário pós-teste e também apoiou a construção de parte do produto.

Com relação aos grupos focais escolhidos, a eleição se deu pela facilidade de acesso, pela diversidade de público e formatos de plano de curso e ainda, pelo número de alunos das turmas, visto que cada tabuleiro do jogo tem a possibilidade de até oito jogadores e foram impressas quatro unidades do produto, que atendem no máximo trinta e dois alunos. A aplicação se dará nos terceiros anos do ensino médio de cada Campus selecionado, porque existe maior possibilidade de que já tenham tido contato com conteúdo de “civilizações précolombianas" na disciplina de História, também porque, possivelmente, terão maior desenvolvimento em língua espanhola que os anos anteriores do ensino médio integrado.

Ao final do processo, o produto será disponibilizado para impressão e montagem na plataforma EDUCAPES para que assim, outros professores possam acessá-lo e utilizá-lo.

As duas aplicações de pesquisa estavam previstas para março e abril de 2020 e estão adiadas por razão da suspensão de aulas por conta da pandemia do COVID-19. Serão realizadas assim que forem retomadas as atividades escolares. As aplicações-teste ocorreram em outubro e dezembro de 2019 e serão relatadas e discutidas no tópico a seguir.

\section{Resultados e discussões}

A primeira aplicação, ainda de um protótipo do que seria o produto, foi realizada dentro do próprio contexto do mestrado. Em outubro de 2019, foi proposto que os produtos fossem apresentados na disciplina de Práticas Educativas aos colegas do Mestrado Profissional em Educação Profissional e Tecnológica para que pudessem testá-lo e enriquecê-lo com sugestões de melhorias e observações. No momento, apenas a primeira parte do jogo estava pronto. Aconteceram 3 rodadas com grupos de 5 pessoas que ao final fizeram suas observações e sugestões de melhorias.

Foi elogiada a relevância do tema, a interatividade e a atratividade do jogo. Também salientaram a questão da cooperatividade entre as personagensljogadores e jogadoras como 
ponto positivo e propuseram um manual de instruções mais detalhado que não deixasse lacunas. Sugeriram também que os objetos que são necessários para desvendar os enigmas do jogo, como chaves e moedas, fossem os próprios objetos, o que tornaria mais atrativo visualmente do que se estivessem apenas ilustrados em cartas.

Atendidas as sugestões de alterações, foi realizada em dezembro de 2019 uma aplicação que visava testar o produto completo em situação real com múltiplos tabuleiros em jogos simultâneos e com um grupo focal que tivesse quantidade e faixa etária semelhante as dos grupos de pesquisa.

O grupo era formado por 22 alunoslas dos três anos do Ensino Médio integrado ao técnico em eventos do Instituto Federal de Brasília, que foram reunidos em um mesmo local devido à pequena quantidade de estudantes que ainda frequentavam as aulas na proximidade do fim do ano letivo. Foram divididos em quatro grupos similares em tamanho, receberam seus tabuleiros e foram convidados a iniciar a rodada. Inicialmente, já se mostraram encantados com o formato do jogo e com a riqueza de detalhes em objetos e ilustração. $\mathrm{Na}$ segunda etapa, que consistia na leitura do manual de instruções e escolha de personagens, esbarramos no primeiro desafio: o manual, que estava grande, já que tentava guardar em si todas as informações necessárias e possíveis respostas a dúvidas que poderiam surgir, não foi lido integralmente por todos os grupos. Apenas um leu mais cuidadosamente e os outros três, ao se assustarem com o tamanho, preferiram tentar começar o jogo $e$ ir buscando as informações conforme acreditassem que fossem necessárias, acarretando uma série de pequenos erros, os quais fizeram com que tivessem que retornar às jogadas e corrigi-las. Este fato fez com que alguns alunos acreditassem que o jogo era difícil, complexo e por isso quisessem desistir de jogar, o que só não aconteceu porque, por ser um jogo coletivo, o abandono de um dos componentes prejudicava o grupo, o qual intercedeu para que ficassem. Outro desafio foi o tempo. Com todas estas questões de reunião de alunos, separação em grupos e euforia no contato com o produto, o tempo de início do jogo foi retardado, o que fez com que um grupo não chegasse ao fim do jogo.

Ao final do tempo planejado, realizamos uma mesa redonda, na qual puderam expor suas opiniões a respeito do jogo e suas sugestões de melhorias. Mais uma vez, a temática foi muito elogiada e mencionaram a inquietação com o fato de que há histórias importantes que 
não são estudadas e que fatos, dados e datas que não os impactam tão diretamente são repetidos à exaustão. Importante também a menção da imposição de papel designado ao gênero que, segundo oslas estudantes, foi e será "desobedecido" sempre que for imposto.

Elogiaram esteticamente o jogo que julgaram atrativo pelas peças e ilustrações. Um dos grupos, que inclusive foi o que melhor se desenvolveu, relatou que já estava familiarizado com a logística de jogos de tabuleiro e RPG, o que deu a eles outra experiência com o produto, mais simplificada e organizada, o que me levou a enxergar que ele poderia estar de fato complexo para os que não são amantes dos jogos ou que não tem experiência com esse formato. Quando questionados sobre o que poderia resolver este problema, sugeriram um vídeo explicativo que substituísse o manual extenso e um demo de simulação coletiva de uma primeira rodada. Acatadas as sugestões, as duas alterações já estão disponíveis para as aplicações de pesquisa.

A construção do produto "Abya Yala em jogo" percorreu caminhos de descoberta teórica e pessoal, e, a oportunidade de vê-lo acontecendo de forma independente, nas mãos de outras pessoas me levou a outro lugar, foi indescritível. Mais do que ver realizar-se um produto que funciona no campo da aplicabilidade e da jogabilidade, ao perceber a diferença colonial, a interculturalidade, a pedagogia decolonial saindo do campo teórico e gerando através de um jogo reflexões, foi inevitável pensar em como teria sido fantástico ter tido contato com esses autores e com estas reflexões quando mais jovem, e o quanto isso teria mudado a forma de me ver, de ver os outros, de ver o mundo em uma fase de tanto conflito interno e externo. Em um produto pedagógico destinado ao ensino de língua estrangeira estão postas as possibilidades de trabalhar as ideias de identidade; pertencimento; colonialidade do saber, do ser do poder e de gênero; e o racismo-sexismo epistêmico que fundamenta essa colonialidade.

\section{Considerações finais}

Ô meu corpo, faça sempre de mim um homem que questiona! (Frantz Fanon, 2008) Neste prelúdio está o que moveu todo o curso da presente pesquisa. Nascida do incômodo de não encontrar espaço no ensino da língua para o seu principal produtor e 
transformador: o falante dela, gerou um produto educacional que tem como norte a promoção do incômodo nos Inas estudantes ao expor, através de um jogo de tabuleiro que trabalha a história não contada de mulheres de Abya Yala, fissuras históricas que omitem na sombra da colonialidade pessoas que desafiaram a normatização colonial de racialização patriarcal, promovendo um outro espaço de interação entre os conhecimentos subalternizados e os ocidentais, refutando a hegemonia de um e a invisibilização dos outros.

As rodas de avaliação e sugestões realizadas no fim das aplicações-teste demonstraram o encantamento com relação ao tema e com o formato escolhido.

O produto, ainda que não tenha sido submetido à todas as aplicações, se mostrou eficaz no que diz respeito à atratividade, ao envolvimento e à mudança de ação. Para as próximas aplicações, esperamos que as modificações realizadas a partir das sugestões dos participantes resolvam as lacunas que restaram com relação à compreensão.

Assim que finalizadas as aplicações e possíveis alterações, o produto será disponibilizado na plataforma EDUCAPES para impressão e utilização, com todas as informações necessárias para que possa ser empregado por docentes e estudantes.

Referências

ANTUNES, I. Língua, texto e ensino: outra escola possível. São Paulo: Parábola, 2009.

BOLÍVAR, S. Carta de Jamaica. Setembro de 1815. Disponível em: https://albaciudad.org/wpcontent/uploads/2015/09/08072015-Carta-de-Jamaica-WEB.pdf, acesso em: 28/04/2020.

CRUZ, E. A. de S.; OLIVEIRA, L. F. de. Penso, mas não existo! Invisibilidade da África nos currículos de história do Rio de Janeiro. Revista Interdisciplinar de Humanidades, v.3, n. 1, p.119, jan-jun 2016.

DECLARACIÓN DE INXIMCHE', 30 de março de 2007. Disponível em: http://www.nacionmulticultural.unam.mx/movimientosindigenas/docs/67.pdf, acesso em $28 / 04 / 2020$. 
DUSSEL, E. Europa, modernidade e eurocentrismo. Em: LANDER, E. (org.). A colonialidade do saber: eurocentrismo e ciências sociais. Perspectivas latino-americanas. Colección Sur, CLACSO, Buenos Aires, 2005.

DUSSEL, E. Transmodernidade e interculturalidade: interpretação a partir da filosofia da libertação. Sociedade e Estado, Brasília, v. 31, n. 1, p. 51-73, Apr. 2016.

ESCOBAR, A. Mundos y conocimientos de otro modo: el programa de investigación de modernidad/colonialidade latinoamericano. Tabula Rasa, n. 1, p. 51-86, Ene.-Dic. 2003.

FANON, F. Pele negra, máscaras brancas. Salvador: EdUfba, 2008.

FERNANDES, D. Práticas de ensino e de avaliação de docentes de quatro universidades portuguesas. Em: Avaliação, ensino e aprendizagens em Portugal e no Brasil: realidades $e$ perspectivas. Lisboa: Educa, 2015. p. 97-135, v. 1.

GROSFOGUEL, R. A estrutura do conhecimento nas universidades ocidentalizadas: racismo/sexismo epistêmico e os quatro genocídios/epistemicídios do longo século XVI. In: Sociedade e Estado, v. 31, n. 1, p. 25-49, 2016.

HALL, S. Identidade e diferença: uma introdução teórica e conceitual. In: SILVA, T. T. (org.), Identidade e diferença: a perspectiva dos estudos culturais. Petrópolis, RJ: Vozes, 2011.

KAPLÚN, G. (2003). Materiais educativos: experiência de aprendizado. Revista Comunicação \& Educação, 271, 46-60. São Paulo, 2003.

KILOMBA, G. Memórias da plantação: episódios de racismo cotidiano. Rio de Janeiro: Cobogó, 2019.

LEITE, P. S. C. Produtos Educacionais em Mestrados Profissionais na Área de Ensino: uma proposta de avaliação coletiva de materiais educativos. Disponível em: https://proceedings.ciaiq.org/index.php/ciaiq2018/article/view/1656, acesso em: 20/03/2020. 
MALDONADO-TORRES, N. Sobre la colonialidad del ser, contribuciones al desarrollo de un concepto. In: CASTRO-GÓMEZ, S.; GROSFOGUEL, R. (org.). El giro decolonial: reflexiones para una diversidad epistémica más allá del capitalismo global. Bogotá: Universidad JaverianaInstituto Pensar, Universidad Central-IESCO, Siglo del Hombre, 2007.

MENDOZA, B. La epistemología del sur, la colonialidad del género y el feminismo latinoamericano. In: Yuderkys Espinosa Minoso (org.). Aproximaciones críticas a las prácticas teórico-políticas del feminismo latinoamericano. Buenos Aires: En la Frontera, 2010.

MIGNOLO, W. Histórias locais/projetos globais: colonialidade, saberes subalternos $e$ pensamento liminar. Belo Horizonte: Editora UFMG, 2003.

MORENO, A. F. B. Educação escolar e cultura(s): construindo caminhos. Revista Brasileira de Educação, 2003, v. 26, nº 1, p. 13-32.

NAVARRO-SWAIN, T. A construção dos corpos: perspectivas feministas. Ilha de Sta Catarina: Editora Mulheres, 2008.

PORTO-GONÇALVES, C. W. Abya Yala. Enciclopédia Latinoamericana. Disponível em: http://latinoamericana.wiki.br/verbetes/a/abya-yala, acesso: 26/03/2020.

PRATT, M. L. Os olhos do império: relatos de viagem e transculturalização. São Paulo: EDUSP, 1999.

QUUIJANO, A. Colonialidade do poder, eurocentrismo e América Latina. In: LANDER, E. (org.). A colonialidade do saber: eurocentrismo e ciências sociais. Perspectivas latinoamericanas. Colección Sur Sur, CLACSO, Buenos Aires, Argentina. p.227-278, 2005.

RUIZ, L.; MOTTA, L.; BRUNO, D.; DEMONTE, F.; TUFRÓ, L. (2014). Producción de materiales de comunicación y educación popular. Buenos Aires: Publicaciones de la Facultad de Derecho y Ciencias Sociales de la Universidad de Buenos Aires.

SARMIENTO, D. F. Facundo: Civilización y barbárie. Santiago do Chile, 1845. 
SEGATO, R. L. Gênero e colonialidade: em busca de chaves de leitura e de um vocabulário estratégico descolonial. E-cadernos CES (Online), v. 18, p. 1-5, 2012. Disponível em: https://journals.openedition.org/eces/1533, acesso em: 20/02/2020.

SEGATO, R. L. Contra-pedagogías de la crueldad. Buenos Aires: Prometeo Libros, 2018.

SILVA, S. G. Jogos Educativos digitais como instrumento metodológico na educação infantil. 2010. Disponível em: http://psicopedagogiabrasil.com.br/, acesso em 13.11.18.

SILVA, T. T. A produção social da identidade e da diferença. Pelotas: Ed. UFPEL, 2011.

SOUZA, L. de M. Inferno Atlântico: demonologia e colonização: séculos XVI-XVIII. São Paulo: Companhia das Letras,1993.

VELASCO, C. G. Brincar, o despertar psicomotor. Rio de Janeiro: Sprint, 1996

WALSH, C. Pensamiento crítico y matriz (de)colonial: Reflexiones latinoamericanas. Quito: Ediciones Abya-yala, 2005.

Data de submissão: 28/03/2020. Data de aprovação: 07/05/2020. 